\title{
The return-to-entrepreneurship puzzle
}

\author{
Ari Hyytinen \\ University of Jyväskylä and Yrjö Jahnsson Foundation \\ Pekka Ilmakunnas \\ Aalto University and HECER \\ and \\ Otto Toivanen \\ Katholieke Universiteit Leuven
}

Discussion Paper No. 322

April 2011

ISSN 1795-0562

HECER - Helsinki Center of Economic Research, P.O. Box 17 (Arkadiankatu 7), FI-00014 University of Helsinki, FINLAND, Tel +358-9-191-28780, Fax +358-9-191-28781,

E-mail info-hecer@helsinki.fi, Internet www.hecer.fi 


\title{
The return-to-entrepreneurship puzzle*
}

\begin{abstract}
The returns to entrepreneurship are monetary and non-monetary. We offer new evidence on these returns using a large sample of genetically identical male twins. Our within-twin analysis suggests that OLS estimates are downwards, and traditional first-differenced panel data estimates upwards biased. We find no differences in the earnings of men with either low or high education. Our within-twin analysis of non-monetary returns shows that entrepreneurs with low education work longer hours and have greater responsibilities, but also face a reduced risk of divorce and less monotonous work tasks. The same does not apply to highly educated entrepreneurs.
\end{abstract}

JEL Classification: L26, J24

Keywords: entrepreneurship, earnings, twin data, education, monetary returns, nonmonetary returns, selection.

Ari Hyytinen

Jyväskylä University School of Business and Economics

P.O. Box 35

FI-40014 University of Jyväskylä

FINLAND

e-mail: ari.hyytinen@jyu.fi
Pekka Ilmakunnas

Department of Economics

Aalto University

P.O. Box 21240

FI-00076 Aalto, Helsinki

FINLAND

e-mail: pekka.ilmakunnas@aalto.fi

Otto Toivanen

Department of Managerial Economics, Strategy and Innovation

Katholieke Universiteit Leuven

Naamsestraat 69

B-3000 Leuven

BELGIUM

e-mail: otto.toivanen@econ.kuleuven.be

* We would like to thank Jaakko Kaprio, William Kerr, Edvard Lazear, Mirjam van Praag and seminar participants at HECER (Helsinki, 2008), EARIE (Toulouse, 2008), the 3rd Nordic Summer Institute in Labour Economics (Aarhus, 2008) and the XXX Annual Meeting of the Finnish Society for Economic Research (Jyväskylä, 2008) for useful comments, Jaakko Kaprio for access to the twin data and Anni Nevalainen and Mari Rantanen for excellent research assistance. This research has been financially supported by the Academy of Finland (project 127796). Toivanen also thanks the Yrjö Jahnsson Foundation for support and Hyytinen the Bank of Finland for hospitality. The usual caveat applies. 
Hardly anyone thinks that the returns to entrepreneurship would not be both monetary and non-monetary. There is less agreement on how large those returns are. Some argue that there is a return-to-entrepreneurship puzzle, i.e., that despite working longer hours and bearing greater risks, entrepreneurs earn on average less than employees (see, e.g., Evans and Leighton 1989, Carrington, McCue and Pierce 1996, Hamilton 2000). ${ }^{1}$ Not all analyses support this view (see, e.g., Fairlie 1995, Berglann, Moen, Røed and Skogstrøm 2011), and some others emphasize the non-monetary returns, such as greater independence and higher job satisfaction. ${ }^{2}$ We provide new evidence on both monetary and non-monetary returns using a large sample of identical male twins. We also provide evidence that entrepreneurial dynamics may invalidate the use of traditional panel data estimators.

While the prior analyses are insightful, they are on balance inconclusive about the importance of the monetary and non-monetary returns to entrepreneurship. Besides differences in the sources of data and subtle measurement issues (see, e.g., Parker 2009 and Åstebro, 2011), there are two potential reasons for this somewhat unfortunate state of affairs: First, unobserved heterogeneity may hamper the inference. A number of the earlier findings are based on cross-sectional analyses that cannot tell apart the implications of unobserved heterogeneity, such as differences in ability (e.g. productivity at work), risk aversion, and willingness to substitute work for leisure. Second, even though there are studies that use panel

\footnotetext{
${ }^{1}$ Evidence for the claim that the self-employed bear greater risk and face a more variable income stream than regular employees can be found from, e.g., Carrington, McCue, and Pierce (1996).

2 A number of cross-sectional studies (e.g. Blanchflower and Oswald 1998, Blanchflower 2000, Hundley, 2001) and also panel studies (e.g. Benz and Frey, 2004, Taylor, 2004, Kawaguchi, 2008, Andersson, 2008) argue that it may be more satisfying to be self-employed than to work as an employee for an organization). Consistent with this, the desire for independence appears to predict entry into self-employment (e.g. Taylor 1996, 2004). Andersson (2008) has examined the health aspects of entrepreneurship and found entrepreneurs to have more mental health problems.
} 
data to control for the unobserved heterogeneity, they implicitly introduce another potential bias. This bias arises because the identification is based on withinindividual (temporal) variation in the data.

Using the within-individual variation for the identification of the returns to entrepreneurship is problematic because of the dynamics of entrepreneurial entry and exit: Those who have just entered may be struggling for survival and thus working longer hours, earning less, and bearing greater risks than the (incumbent) entrepreneurs. They may also enter entrepreneurship from a state that is unusually bad, for example from unemployment or from an unsatisfying job. The direction of the bias would then depend on the relative strength of these two effects. Using entrepreneurial exits for identification is at least as problematic, because most of the entrepreneurial (self-employment) spells are very brief both in the US (see, e.g., Evans and Leighton 1989, Bruce and Schuetze 2004) and in Europe (see, e.g., Taylor 1999, Hyytinen and Rouvinen 2008). They are brief because many of the new entrepreneurs fail soon after entry. This means that in studies making use of panel data, within individual variation at the end of an entrepreneurial spell may arise from the labor market switches of those who lost the battle for survival (whereas the most successful entrepreneurial spells are right-censored). It is also possible that exit from entrepreneurship may lead into a worse than average employment state. Standard panel estimators, such as the first-differencing (FD) or the fixed effects (FE) -estimators, identify returns to entrepreneurship from this type of variation or assume that contemporaneous or expected future shocks do not affect occupational choices. We show that these worries are with some foundation in the data we use.

This paper offers new evidence on the returns to entrepreneurship using data from a large sample of genetically identical twins - monozygotic (MZ) twins - 
that has been matched to linked employee-employer data. ${ }^{3}$ These data allow us to focus on within twin pair variation. Twin differencing controls for genetic factors that, we argue, are one of the prime sources of unobserved heterogeneity. Supporting this view, Nicolaou, Shane, Charkas, Hunkin and Spector (2008), Nicolaou and Shane (2009) and Shane, Nicolaou, Cherkas, and Spector (2010) explain that the tendency of individuals to become entrepreneurs depends on genetics for four main reasons: First, certain genetic compositions have a direct effect on the chemical mechanisms in an individual's brain that may expose her to entrepreneurship (by, e.g., influencing how she perceives risk taking). Second, they contribute to the development of personality traits (e.g., extraversion) that almost certainly are beneficial in entrepreneurship (see also Nicolaou, Shane, Charkas and Spector 2008). Third, certain genetic compositions make an individual more responsive to environmental stimuli (e.g. business opportunities). Finally, genetic factors affect the likelihood than an individual self-selects into environments supportive to entrepreneurship (leading to so called gene-environment correlation). Yet another reason why comparing (monozygotic) twins controls for the unobserved heterogeneity is that besides the same genetic environment, they share the same family background and typically experience more similar environments than for example non-twin siblings or children of different families do. This means that twin differencing is robust to, e.g., intergenerational correlation in selfemployment (Dunn and Holtz-Eakin 2000), as it does not rely on sample variation between families.

Our within twin pair analysis of the monetary returns indicates that the monetary returns obtained using OLS are downward biased. The results obtained

\footnotetext{
${ }^{3}$ We use a Finnish twin data set. Because of the high response rate, the data set is as large as the twin data sets in other Nordic countries (Denmark, Norway and Sweden).
} 
using traditional panel data estimators, particularly the FD-estimator, are upward biased. In within-twin analysis we find no systematic differences between the earnings in entrepreneurship and in paid employment. This result holds irrespective of the educational level (low or high) of the individuals. Our results thus suggest that there is no returns-to-entrepreneurship puzzle.

Looking at non-monetary returns, we find that entrepreneurs with a low education work longer hours and have more responsibilities at work. On the positive side, they face more often non-monotonous work, and have a lower risk of divorce. Highly educated entrepreneurs do not experience these counter-balancing non-monetary returns of entrepreneurship.

The rest of the paper is organized as follows: In the next section, we study the monetary returns to entrepreneurship. After discussing the identification of entrepreneurial returns with different estimators we describe the data; compare the estimation samples of the traditional panel data estimators and the within-twin estimator; look at the average (log) earnings of those observations used for identification of returns to entrepreneurship with different estimators; and present the estimation results. In the third section we analyze empirically the non-monetary returns to entrepreneurship. Section four concludes.

\section{$2 \quad$ Monetary returns to entrepreneurship}

\section{$2.1 \quad$ Econometric framework}

We build our empirical analysis of monetary returns to entrepreneurship on the following Mincer-type earnings equation:

$$
y_{i j t}=\alpha+\gamma E N T_{i j t}+X_{i j t}{ }^{\prime} \lambda+\varepsilon_{i j t}
$$


where $y_{i j t}$ refers to the (natural logarithm of) earnings of individual $i(i=1,2)$ from pair (family) $j(j=1,2, \ldots, N)$ at time $t\left(t=1,2, \ldots, T_{i j}\right), E N T_{i j t}$ is a dummy variable indicating whether a person is an entrepreneur (self-employed) at time $t, X_{i j t}$ is a vector of control variables, and $\varepsilon_{i j t}$ is an error term.

The parameter of interest is $\gamma$, which measures in percentage terms how much more (or less) entrepreneurs earn, on average, when compared to employees. While $\gamma$ is assumed to be constant here for expositional simplicity, we allow it to vary with education in the empirical analysis.

The error term is assumed to be

$$
\varepsilon_{i j t}=\beta A_{i j}+v_{i j t}
$$

where $A_{i j}$ reflects (time-invariant) unobserved heterogeneity and where $v_{i j t}$ is an i.i.d. random component. In this formulation, $A_{i j}$ is typically interpreted to reflect the unobserved ability of individual $i$ of pair $j$ (“innate ability”), but it could also reflect, e.g., risk aversion, personality traits, and preferences. ${ }^{4}$

Estimating (1)-(2) by standard cross-sectional methods, such as OLS, rests on the assumption that either ability does not affect earnings (i.e., $\beta=0$ ) or that conditional on $X_{i j t}$, ability is uncorrelated with the decision to become an entrepreneur. The standard panel data estimators, such as FD or FE, may also be unreliable, because they tend to pick up a peculiar entry and/or exit phase of the dynamics of the earnings of entrepreneurship.

To see how, consider first the FD-estimator. The variation that this estimator utilizes in identifying the coefficient of interest, $\gamma$, becomes salient if we firstdifference (1) to obtain

\footnotetext{
${ }^{4}$ One can think of it as a sum of the family (pair) effect and the deviation of individual $i$ from the family average.
} 


$$
y_{i j t}-y_{i j t-1}=\gamma\left(E N T_{i j t}-E N T_{i j t-1}\right)+\left(X_{i j t}-X_{i j t-1}\right)^{\prime} \lambda+\left(v_{i j t}-v_{i j t-1}\right)
$$

Equation (3) shows that while FD can remove the ability bias, it effectively identifies $\gamma$ through variation in i) the differences of the variables in the last year of employment prior to entrepreneurship and the first year of entrepreneurship and 2) the differences in the variables in the last year of entrepreneurship and the first year of employment post entrepreneurship. This is so because the difference $E N T_{i j t}-E N T_{i j t-1}$ is zero in all the other cases. The direction of the bias depends on how the last and first years of entrepreneurship and employment differ from the average years of entrepreneurship and employment. If there is for example a dip in earnings before a switch to entrepreneurship (similar to Ashenfelter's dip (Ashenfelter, 1978) in the program evaluation literature) and/or a drop in employment income after an exit from entrepreneurship, the FD-estimator would be biased upwards.

The direction of bias is less clear in the case of a FE estimator. The variation that the FE-estimator utilizes becomes salient from

$$
y_{i j t}-\bar{y}_{i j}=\gamma\left(E N T_{i j t}-\overline{E N T}_{i j}\right)+\left(X_{i j t}-\bar{X}_{i j}\right)^{\prime} \lambda+\left(v_{i j t}-\bar{v}_{i j}\right) .
$$

Like the FD-estimator, this method can remove the ability bias. However, it also relies on the potentially problematic within-individual variation of the data, as $E N T_{i j t}-\overline{E N T}_{i j}$ varies only for those persons who switch their occupation during the sample period. For mobile individual $i$ from pair $j$, the differences remain constant until her occupation switches. The consistency of the FE-estimator requires that the expected value of the random component of (2) is zero, conditional on the ability and the leads and lags of the explanatory variables. This strict exogeneity condition is violated if individuals make career choices based on their expectations of future earnings shocks or if current earnings shocks determine future ca- 
reer choices. Thus, if there is for example a drop in earnings in the last year of employment prior to entrepreneurship and if this drop in part determines the subsequent career choice, the condition is violated.

Twin-differencing can control for unobserved heterogeneity without relying on the dynamic variation in the data (see, e.g., Ashenfelter and Krueger 1994, Ashenfelter and Rouse 1998, Bonjour et al. 2003, Isacsson 2007, Gurrin et al. 2006 and Carlin et al. 2005). Assuming that $A_{1 j}=A_{2 j}$ for genetically identical MZ twins, twin differencing (1) and (2) gives

$$
y_{1 j t}-y_{2 j t}=\gamma\left(E N T_{1 j t}-E N T_{2 j t}\right)+\left(X_{1 j t}-X_{2 j t}\right)^{\prime} \lambda+\left(v_{1 j t}-v_{2 j t}\right) .
$$

This shows that the parameter of interest can be identified from a single cross section through variation in the within pair differences of the variables, calculated for each individual within a twin pair. Standard OLS estimation of (5) (or (5) pooled over time) is a way to implement the within twin (WT) pair estimator. It removes the ability bias and does not use variation around the entries and exits. The WTestimator assumes, however, that conditional on the observables, differences in twins' career choices (within pair differences in $E N T_{i j t}$ ) represent random variation and thus that the conditional expectation of the differences of the individual earnings shocks is zero within each pair. For now, we acknowledge that this assumption can be problematic (see, e.g., Bound and Solon 1999, Neumark 1999) and postpone the discussion of this potential problem to a later section.

It is important to note that the WT estimator uses different individuals for identification than the traditional panel data estimators. As noted above, the FD and FE estimators do not use the individuals who do not switch occupation, whereas the WT estimator uses them, as long as the individuals within the twin pair are in different occupations. On the other hand, the WT estimator does not use some of the individuals included in FE or FD, i.e., those twin pairs where the 
twins switch occupation at the same time but there is no within-twin pair difference in occupation.

\subsection{Data and definition of variables}

Our data are based on a sample of twins that were initially identified for a large scale survey of Finnish twins born before 1958. The survey was carried out at three points in time: 1975, 1981, and 1990, and each time, respondents were asked a battery of questions related to their between-twin differences, their medical history, their self-reported experiences of "shocks to living quality", their living habits, and their occupation. For a detailed description of these surveys and for related information, see Kaprio et al. (1979), Kaprio and Koskenvuo (2002), and www.twinstudy.helsinki.fi. The surveys cover almost all same sex twin pairs alive in Finland at the time of each survey and born before 1958. The original data contain 11927 twin pairs and thus 23854 individuals.

The twin surveys have for this study been matched with the Finnish Longitudinal Employer-Employee Data (FLEED) data base of Statistics Finland. FLEED is a combination of various registers on individuals and firms and it covers years from 1988 to 2004. The information on individuals in FLEED is based on the Employment Statistics (ES) data base, which includes information on the labor market status of individuals and their background characteristics from different administrative registers. It covers effectively the whole working-age population of Finland, so we can track over time the labor market behavior of the twins who are in the original twin surveys.

The main data that we use to estimate earnings equations of type (1)-(2) consist of those twin pairs for which both individuals can be observed to be alive throughout the FLEED sample period and for which there are no missing data in 
the key dependent or explanatory variables. To be in line with the previous research on entrepreneurship, we drop farmers (i.e., twin pairs of which at least one is a farmer). We concentrate on male twins to avoid the problem of simultaneously estimating the entrepreneur-employee pay gap, the gender pay gap, and the effects of gender differences in labor supply. In the estimation sample we have 7187 observations of male MZ twins.

In the FLEED data the definition of an entrepreneur is based on whether the person belongs to the pension system of entrepreneurs. Based on this information we define dummy $\mathrm{ENT}_{i j t}$ which equals to one if person $i$ from pair $j$ is an entrepreneur at $t$ time and is zero otherwise.

The FLEED data contain several income and earnings variables, which are based on tax registers. In this study, we employ the sum of wages and salaries, entrepreneurial income, and capital income. ${ }^{5}$ This earnings variable, EARNINGS, can be computed for 1993-2004 and is deflated with the consumer price index. The dependent variable that we use in the regression analysis is the natural logarithm of EARNINGS (LN(EARNINGS)).

The control variables in the earnings equation $\left(X_{i j t}\right)$ are drawn from the FLEED data and from the survey. They can be divided into two subsets. The first subset of control variables include age (AGE in years; we employ a fourth order polynomial), weight (WEIGHT90 in 1990 from the 1990 survey, in kilograms), height (HEIGHT90 in 1990 from the 1990 survey, in centimetres), body mass index (BMI90 in 1990), whether the person had in 1990 experienced unemployment less than five years ago (UNEMPSHOCK_NEW90, from the 1990 survey),

\footnotetext{
${ }^{5}$ Wages and salaries include income paid to persons during the year in pay - either in money or benefits in kind. Wages and salaries also include overtime compensations, income received from secondary jobs, and (realised) incentive stock options. Entrepreneurial income includes income from agriculture and forestry, business activity and business group, and copyright fees. See http://www.stat.fi/ meta/kas/index_en.html (accessed 30/1/2008).
} 
whether the person had in 1990 experienced unemployment more than five years ago (UNEMPSHOCK_OLD90, from the 1990 survey), marital status in 1990 (MARITAL_STATUS90, from the 1990 survey), whether the person was lighter than his co-twin in 1990 (LIGHTER90, from the 1990 survey), and whether the person was a current daily smoker in 1990 (SMOKER90, from the 1990 survey). Except for age, all of these variables are time invariant over the sample period. Though these variables (except AGE) drop out in FD and FE estimations, in WT estimations they are included (but AGE drops out). They allow us to narrow down, relative to many other studies using twin data, the possibility that withintwin differences (not driven by genetics but correlated potentially with the career choices) cause a bias in the results.

In the second subset of controls all variables vary (at least for some individuals) over time. They come from the FLEED data and include a dummy for high education (EDUC = 1 if at least a bachelor's degree, $=0$ otherwise), marital status (MARITAL_STATUS $=1$ if married, $=0$ otherwise), ownership of a house or a dwelling (HOUSE_OWNER = 1 if owns one, $=0$ otherwise), presence of children under age of 7 in the family (CHILD_7, count), presence of children between 7 and 18 years of age in the family (CHILD_7_18, count), ownership of taxable wealth (DUM_WEALTH $=1$ if the amount of taxable wealth $>0,=0$ otherwise), and amount of taxable wealth $(\mathrm{LN}(\mathrm{WEALTH})=$ natural logarithm of $(1+$ taxable wealth)). We display the descriptive statistics of these variables in the Appendix.

\subsection{Comparison of estimation samples}

As is clear from the above discussion, the different estimators rely on different parts of the estimation sample for identification. One way to look at the differences is to compare the frequency and overlap of those observations that yield 
identification. This comparison shows that $6.5 \%$ of the observations in our data are from individuals who switch occupation at least once during our observation period. It is this subsample whose observations are used for identification with the traditional panel data estimators. The FD estimator will only use a (particular) subset of these observations, the FE estimator all these observations. In comparison, $11.4 \%$ of our observations are such that the twins are in different occupations in a given year; it is these observations that the within-twin estimator uses for identification. The correlation between the dummies indicating inclusion in these samples is only 0.2 and the samples share only 724 observations, suggesting that very different observations and (observations on) different individuals deliver identification for the different estimators.

\section{[INSERT TABLE 1 ABOUT HERE]}

Turning then to the observations delivering identification for the traditional panel data estimators, we calculated the means of (log) earnings (LN(EARNINGS)) for 1) the observations that are a year before individual $i$ from pair $j$ changes from being an employee to becoming an entrepreneur; 2) the first year of entrepreneurship; 3) the last year of entrepreneurship; 4) the first year after entrepreneurship; 5) and averages for the periods prior to entrepreneurship, of entrepreneurship, and after entrepreneurship, always excluding the years of occupational change, and the years just before and just after.

The FD estimator uses just the year of occupational change and the year before. As Table 1 shows, the mean LN(EARNINGS) in the year before an individual became an entrepreneur is 10.08 , while the mean for the first year of entrepreneurship is 10.27 , suggesting a return of $10.27-10.08=0.19$. Using the last year of entrepreneurship (average 10.03) and first year after entrepreneurship (9.89) suggest a return of 0.14 . 
We then compare the last year before entrepreneurship and the first year after entrepreneurship to the average LN(EARNINGS) of the same individuals in other years of paid employment. The difference between LN(EARNINGS) in the last year before entrepreneurship and the average LN(EARNINGS) prior to entrepreneurship (excluding the last year) is -0.12 , i.e., these individuals earn less in the last year before becoming entrepreneurs than they have earned in prior years. The difference is not statistically significant, but that is probably mainly due to the small number of observations we have for the earnings in the last year before entrepreneurship. The first year of paid employment after entrepreneurship yields earnings that are statistically significantly lower than the average earnings in paid employment both before and after entrepreneurship. These differences are large, too. Even if there were no systematic differences in the earnings of the entrepreneurs in their first, last, and other years, these differences would suggest that the FD estimates of returns to entrepreneurship should be upwards biased.

A comparison of the income of entrepreneurs in different years reveals some systematic differences, however. The average LN(EARNINGS) in the first year of entrepreneurship is 10.27, compared to an average of 10.02 in all other years of entrepreneurship bar the first and the last. The difference is 0.24 . Again, it seems that the reason for the statistical insignificance is the small number of observations. In contrast, the earnings in the last year of entrepreneurship, at 10.03, are close to the average of all years in entrepreneurship bar the first and the last.

Taken together, these differences suggest that the FD estimator would yield an upward biased estimate of returns to entrepreneurship because of three reasons: 1) the earnings in the last year of paid employment prior to becoming an entrepreneur are lower than in other years of paid employment; 2) the earnings in the first year of paid employment after entrepreneurship are lower than in other years of 
paid employment; and 3) the earnings in the first year of entrepreneurship are higher than in other years of entrepreneurship. ${ }^{6}$

The FE estimator uses all the observations of the individuals that change occupations. However, the strict exogeneity assumption on which the FE estimator's consistency rests requires in our context that individuals change occupation neither because of this year's nor because of future years' earnings shocks. The fact that the earnings of those individuals who change occupations are lower in the last year before entrepreneurship than in the other years of paid employment prior to entrepreneurship suggests that the strict exogeneity assumption may be violated. Similarly, the fact that the earnings in the first year of entrepreneurship are higher than in the other years of entrepreneurship suggests that knowledge of this earnings shock may have contributed to the fact that these individuals changed jobs. This pattern would be another violation of strict exogeneity.

\subsection{Empirical analysis}

\section{Main results}

We present our main results for the earnings regressions in Table 2. These results are based on estimations that include year dummies and both the register and survey based subsets of control variables. To allow for heterogeneous returns to entrepreneurship, we include the interaction between ENT and EDUC in all regressions. Besides the coefficients of ENT, EDUC and the interaction term that are of primary interest to us, the table displays the (differenced) coefficients and $p$ values from the Wald tests that contrast the earnings of the entrepreneurs with

\footnotetext{
${ }^{6}$ The data also confirm the previous findings that the variance of earnings is higher for enterpreneurs than for employees. The standard deviation of LN(EARNINGS) (excluding the first and last year) is 1.16, that of employment income prior to entrepreneurship 0.71 and that of employment income after entrepreneurship 0.59 .
} 
high (low) education to those of the employees with high (low) education. Standard errors are clustered in all cases by twin pair, which allows for within individual and within twin correlation. ${ }^{7}$

Column (1) contains the OLS estimates produced by pooling the data of male MZ twins over the whole FLEED sample period 1993-2004. Columns (2)(4) display the FD, FE and the WT estimates. OLS produces highly significant coefficients for both the entrepreneur as well as the high-education dummies, while the other estimators deliver imprecise point estimates.

\section{[INSERT TABLE 2 ABOUT HERE]}

The implied returns to entrepreneurship are displayed in the lower panel of the table. OLS produces significant - both in statistical as well as in economic terms negative returns to entrepreneurship irrespective of the educational level. The FD return point estimates, while imprecise, are positive and large. The FE estimates are much more moderate in absolute value, and clearly insignificant. While the FE estimate for entrepreneurs with a low education level is close to the WT estimate in column (4), the estimate for highly educated entrepreneurs is clearly larger than the WT estimate. The WT estimates suggest essentially zero returns to entrepreneurship for those with a low level of education, while the point estimate for those with a high level of education is negative and large in absolute value. It is, however, statistically insignificant.

Taken together, the OLS estimates are clearly downward biased; the FD, and to a lesser extent the FE estimates, upward biased compared to the WT estimates. The WT estimates suggest no monetary returns to entrepreneurship.

\footnotetext{
${ }^{7}$ The results are robust to using alternative levels of clustering (e.g. individual only), and to not clustering at all.
} 


\section{Robustness analysis}

Our empirical analysis is motivated by the view that identifying returns to entrepreneurship from within-individual variation over time is challenging, because the dynamics of entrepreneurial entry and exit is of peculiar kind. Data on genetically identical twins allows one to circumvent that problem, because twin differencing uses a different dimension of the data and because it still enables one to control for an unusually diverse sources of unobserved heterogeneity (ability, preferences, traits, family effects, etc). However, as the econometric literature on the returns to education shows, twin differencing is not a panacea either.

The first, but somewhat less thoroughly studied problem is unobserved heterogeneity within twin pairs. The consequence of this heterogeneity is that while twin differencing takes care (“differences out”) much of the endogenous variation in the explanatory variable(s), it does not necessarily eliminate it (Griliches 1979, Bound and Solon 1999, Neumark 1999). If that is the case, the (in)consistency of the WT estimator depends on whether the within twin pair differences that lead to variation in occupational choices also have a direct effect on the earnings (and how the non-earnings aspects of work are perceived). ${ }^{8}$

The second problem with twin differencing is that it may aggravate measurement error in the (key) explanatory variables (Griliches 1979, Ashenfelter and Krueger 1994). Panel data approaches may suffer from a similar problem (see e.g. Rosenzweig and Wolpin 2000), but the fact that the FE and FD estimators rely on differencing in a different dimension means that one cannot easily draw general conclusions on the degree to which different estimators are affected by a given level of measurement error. Assuming that only the key explanatory variable of

\footnotetext{
${ }^{8}$ It is worth pointing out that this not the same as the requirement that monozygotic twins should be precisely identical.
} 
interest, the occupational status ENT, is measured with error, the issue is to what extent the variation induced by measurement error is present in the differenced explanatory variable.

It is hard to tell how severe these problems are in our case. Despite their identical genetic endowment at the DNA sequence level, family background and experiences of very similar environments, we cannot completely rule out unobserved heterogeneity within twin pairs. This heterogeneity may be attributed, i.a., to prenatal and birth effects, chorionicity effects, and epigenetic effects. To the extent that there are such differences, the (twin-differenced) control vector in the WT estimations is presumed to capture them. In our estimations this control vector is unusually extensive relative to many other studies using twin data and ought to narrow down the possibility that within-twin differences not driven by genetics but correlated potentially with the career choices and earnings cause a bias in the results.

We cannot completely rule out the measurement error problem either. The entrepreneurship indicator ENT is based on the pension register. Individuals who are not majority owners of their business are not necessarily classified as entrepreneurs there, although they may well regard themselves as such. Moreover, we want to err on the conservative side and acknowledge therefore that also the indicator for high education, EDUC, may contain measurement error. This variable is based on degrees completed and may therefore give an imperfect measure if the individuals have been in higher education but for some reason have never finished their studies. The estimation problem that the potential measurement error in the two indicators causes can in principle be addressed by applying the method of instrumental variables to the twin-differenced data (called WT-IV below). In twin studies that focus on the effect of schooling on earnings, the standard solution - 
suggested originally in Ashenfelter and Krueger's (1994) study - is to resort to IV estimation, using the level of schooling that individual $i$ from pair $j$ reports for his twin as an instrument for the twin's level of schooling. ${ }^{9}$

We have alternative measures of entrepreneurship and education, which are based on the survey of twins, instead of the register data. We have estimated the within twin pair differenced model by using the within twin pair differences of the self-reported entrepreneurship status (dummy) and the self-reported high education level (dummy), both measured in 1990, as instruments for the within twin pair differences of ENT and EDUC, respectively.

The first two columns of Table 3 show the WT-IV estimates with either ENT or EDUC instrumented, whereas in the third column, both entrepreneurship and education are instrumented. When we instrument only ENT and its interaction with EDUC (column 1), the estimates are relatively close to our WT estimates. As can be read from the bottom of part of the table, these estimates suggest that the earnings for the entrepreneurs with either low or high education are lower than the annual earnings of the men in paid employment with similar education. The estimates are however not statistically significantly different from zero.

When either only EDUC and the interaction term (column 2) or ENT, EDUC, and their interaction (column 3) are instrumented, especially the estimate of the coefficient of the education variable is quite large. The standard errors also increase, so the coefficients are not significant. What is a bit disturbing here is that the instrument for EDUC seems to be much weaker than the instrument for ENT, as evidenced by Shea's partial R-squared measures (Shea 1997). This finding casts doubt on the reliability of the WT-IV results of columns (2) and (3). If we

\footnotetext{
9 The WT-IV estimator is not trouble-free as it may, for example, aggravate the bias when there are within twin pair differences in ability (Bound and Solon 1999, Neumark 1999).
} 
took these estimates at face value, columns (2) and (3) would suggest that that the earnings of the entrepreneurs with low education are smaller and those with high education larger than the earnings of the men in paid employment with corresponding education. However, none of these return differences are statistically different from zero.

\section{[INSERT TABLE 3 ABOUT HERE]}

To explore the robustness of the WT-IV findings, we used within twin pair difference in the self-reported years of education (self-reported level of education converted to years) as an alternative instrument for within twin pair difference in EDUC. For brevity, we do not report them in detail. Suffice it to say, the estimated differences in the returns were much lower than those in Table 3, and our conclusions on their non-significance did not change.

So far we have focused on monetary returns to entrepreneurship. However, the peculiar dynamics of entrepreneurship may also affect the estimates of the non-earnings aspects of the returns to entrepreneurship. We now turn to them.

\section{$3 \quad$ Non-monetary returns to entrepreneurship}

\subsection{Econometric framework}

To provide a framework for the subsequent discussion, let $w_{i j}$, denote a binary variable, with 1 indicating the presence of a positive non-earnings aspect of work and life for an individual $i$ from pair $j$ at time $t$, and 0 otherwise. We work with the (unobserved) propensity at which such aspects are present in a person's work and life and assume that there is a latent (unobserved) variable, $w_{i j t}^{*}$, such that $w_{i j t}=1$ if $w_{i j t}^{*}>0$ and $w_{i j t}=0$ if $w_{i j t}^{*} \leq 0$. With a slight abuse of our earlier notation, the latent variable follows 


$$
w_{i j t}^{*}=\alpha+\gamma E N T_{i j t}+X_{i j t}{ }^{\prime} \lambda+\varepsilon_{i j t} .
$$

The final term in (6) is $\varepsilon_{i j t}=\beta A_{i j}+v_{i j t}$, where $v_{i j t}$ has a standard logistic distribution with mean zero and variance $\pi^{2} / 3$.

Estimating (6) by standard Logit rests on the assumption that either ability (or time-invariant preferences for, say, independence) does not affect nonearnings aspects of entrepreneurship or that conditional on $X_{i j t}$, ability is uncorrelated with the decision to be an entrepreneur. If these assumptions do not hold, the standard Logit estimator is inconsistent.

The standard way to control for unobserved heterogeneity $A_{i j}$ in the case of discrete dependent variable and panel data is to use the method of conditional maximum likelihood, i.e., the fixed-effects logit (FE-logit, see, e.g., Chamberlain 1980, Wooldridge 2002, p. 490-491). Two important properties of this estimator are that it allows $A_{i j}$ to be arbitrarily related to $\left\{E N T_{i j t}, X_{i j t}\right\}$ and that it only uses observations that change from one period to the other. For example, if $T=2$, one can estimate the parameters of interest $\left(\gamma, \lambda^{\prime}\right)$ by considering only the individuals for whom $w_{i j 1}+w_{i j 2}=1 .{ }^{10}$ In essence, the estimation involves using a binary logit model for changes in status $\left(w_{i j}=(0,1)\right.$ coded as 1 and $w_{i j}=(1,0)$ coded as 0$\left.)\right)$ as the dependent variable, explained by differences over time of the original explanatory variables. However, neither $\operatorname{Pr}\left[w_{i j}=(1,0) \mid w_{i j 1}+w_{i j 2}=1\right]$ nor $\operatorname{Pr}\left[w_{i j}=(0,1) \mid w_{i j 1}+w_{i j 2}=1\right]$ is a function of $\gamma$ if $E N T_{i j 2}-E N T_{i j 1}=0$. This means that the variation from which $\gamma$ is identified comes from within-individual varia-

\footnotetext{
${ }^{10}$ The intuition is that individuals for which $w_{i j t}$ is always either one or zero are not informative about $\left(\gamma, \lambda^{\prime}\right)$ : For them, the outcome can be rationalized either by extremely large or extremely small values of $A_{i j}$ for any values of $\left(\gamma, \lambda^{\prime}\right)$.
} 
tion in $E N T_{i j t}$, i.e., from the labor market switches of those who either enter or exit entrepreneurship. Therefore, we encounter the same problems as with the FD estimator in the linear panel data case. These arguments generalize to $T>2$.

The method of twin differencing can also be used when the dependent variable is discrete, like our measures of the non-monetary attributes of entrepreneurship. To see how, take only one cross-section (i.e., $T_{i j}=1$ for all $i$ and $j$ ) and consider individual $(i=1,2)$ and twin pair $(j=1, \ldots, N)$ to be the dimensions of the data. Assuming, as before, that $A_{1 j}=A_{2 j}$ for the MZ twins in (6), it is possible to apply a conditional Logit estimator: Now the estimation uses only the twin pairs in which only one of the twins has the particular positive non-pecuniary aspect, i.e., $w_{1 j t}+w_{2 j t}=1$ (where $t=1=T$ in this example). The explanatory variables are within twin pair differences and, as a consequence, the $\gamma$ parameter is identified through within twin pair variation. This model can be estimated by the method of conditional maximum likelihood, i.e., by a “within twin” Logit (called WT-Logit below).

\subsection{Data and definition of variables}

To estimate the non-monetary returns to entrepreneurship, we only use the data that come from the three surveys of Finnish twins born before 1958, carried out in 1975, 1981, and 1990. The variables are derived from a battery of questions related to the between-twin differences, twins' medical history, their self-reported experiences of "shocks to living quality", their living habits, and their occupation. ${ }^{11}$

\footnotetext{
${ }^{11}$ Of the 23854 individuals, 45\% responded to all three waves of the survey, 40\% miss one wave, and $15 \%$ miss two waves. Out of the possible 35781 twin-pair observations (had both twins of each twin pair always responded, i.e. 3 x 23854/2) we obtain 70\%, i.e., we have 24979 twin-pair observations from the surveys.
} 
We use only male MZ twin pairs in the estimations that we report below. In the pooled data there are 4686 such male MZ twin pair observations, for which the information on entrepreneurial status is available for both twins. The number of observations available for each dependent variable varies because not all questions from which we derive our indicators of non-monetary earnings have been asked in all of the survey waves.

The information on entrepreneurship is based on the survey respondents' answers to a question about their occupational status. Based on the answers, we let ENT equal to one if person $i$ from pair $j$ is an entrepreneur at time $t$ and is zero otherwise.

The surveys provide us with three groups of variables that in different ways describe aspects of life which entrepreneurship could influence. The first set of variables is related to work, the second to various shocks experienced, and the third to health and habits. The questions are framed in different ways: Some of the answers are binary variables, some counts, some on a Likert scale, and some continuous. To be able to use a common model for all of the survey questions, we have transformed the variables to binary ones, with 1 indicating a positive outcome or aspect.

In the first group we have the following variables: Non-monotonous work (= 1 if work is not very monotonous; best two cases in a four-point scale, $=0$ otherwise), No overtime (= 1 if overtime hours have, on average, been less than one per day during the last year, $=0$ otherwise), Working at most 40 hours (= 1 if average weekly working time at most 40 hours, $=0$ otherwise), Influence on pace of work (= 1 if able to choose work pace; best two cases in a three-point scale, $=0$ otherwise), and Influence on working methods (= 1 if can influence working methods; best two case in a three-point scale, $=0$ otherwise). 
In the second group we have indicators for the following positive "shocks" (or absence of negative "shocks"), each one defined as something that has happened during the last five years: No divorce or separation, No increase in conflicts with spouse, No significant increase in responsibilities at work, No significant increase in work load, Significant positive change in life, Significant positive change in work life, and Significant positive change in general living conditions.

In the third group we have the variables Moderate drinking pattern $(=1$ if drinks less frequently than once a month during the same occasion more than five bottles of beer or more than a bottle of wine or more than half a bottle of hard liquor or equivalent quantities of other drinks, $=0$ otherwise), Moderate smoking (= 1 if not a heavy smoker; three best cases in a four-point scale, $=0$ otherwise. This means smoking less than 25 cigarettes a day), No diagnosed diseases ( $=1$ if no diagnosed disease, $=0$ otherwise), as well as the following indicators of the use of medication during the last year ( $=1$ if the person has not used; $=0$ if use in the range of on less than 10 days to over 180 days): No pain killers, No tranquillizers, and No antacids.

The controls used in the analysis of non-monetary earnings are drawn from the surveys. They are weight (WEIGHT in the survey year, in kilograms), height (HEIGHT in the survey year, in centimetres), body mass index (BMI in the survey year), dummy for high education (EDUC, which equals to one if the person has a bachelor degree or has studied at university at least for a year after high school), and an indicator for marital status (MARITAL_STATUS $=1$ for married or cohabiting during the survey year, $=0$ otherwise).

Again, the descriptive statistics of these variables can be found in the Appendix. 


\subsection{Empirical analysis}

\section{Main results}

Before going into the estimation results, three aspects of the WT-Logit estimations are worth mentioning: First, only a few of the dependent variables are available for all of the three waves (and even they are not necessarily in exactly identical form), as many of the questions have been asked only once or twice. We cannot therefore present a systematic comparison between the traditional FE-Logit and WT-Logit estimators. We thus focus on WT-Logit estimations and treat the data as a panel with dimensions MZ twin pair and individual (and wave). In this set up, one wave (i.e., a cross-section) is sufficient for WT-Logit estimations and thus to produce estimates based on twin-differencing. In the analysis that follows we pool the waves for estimation and include survey year dummies. Note that since some of the variables are available in one or two waves only, the number of observations varies in the estimations.

Second, our basic results for the non-monetary returns are based on estimations that use the above described set of (survey-based) control variables in addition to survey year dummies. To allow for heterogeneous non-monetary returns to entrepreneurship, we include in all regressions the interaction between ENT and EDUC.

Third, because of the conditioning in the maximum likelihood estimation, only those twin pairs are effectively used in each estimation for whom the dependent variable has variation within a twin pair. If, for example, both twins of a particular pair always have non-monotonous work, the pair is not included in the estimation. As a result, the effective estimation samples reported in the estimation table are (much) smaller than the initial pooled survey sample of male MZ twins. 
Panels A, B and C of Table 4 present the results for the WT-Logit estimations. The dependent variables are the work-related indicators in Panel A, the various shocks to work and life in Panel B and the health-related indicators in Panel C. In each case we present only the coefficients of ENT, EDUC and their interaction. Since the dependent variables are coded so that 1 indicates a positive aspect, a positive coefficient is suggestive of non-monetary returns to entrepreneurship. In the lower part of the table we present $p$-values from the Wald tests that contrast the non-monetary returns of the entrepreneurs with high (low) education to those of the employees with high (low) education. The last entry in each column is the $p$-value from a Wald test of the joint significance of all the unreported controls.

For entrepreneurs with a low level of education, we find the following: They work more often more than 40 hours than employees, and they work more often overtime. The probability of no significant increase in responsibilities at work is lower for entrepreneurs with low education than for the similarly educated employees. At the same time, the work of entrepreneurs with low education is more often non-monotonous and their risk of divorce is lower.

\section{[INSERT TABLE 4 ABOUT HERE]}

The results for the highly educated entrepreneurs are quite different, as none of the above results hold for them. Nor is there robust evidence of other types of non-monetary returns for them. ${ }^{12}$

\footnotetext{
${ }^{12}$ Besides those studied in Table 4, there are other questions related to health and habits in the surveys, such as those measuring quantitatively the respondent's alcohol consumption or asking the respondent's use of heart medication and sleeping pills. Unfortunately, there appears to be too little within twin variation in these measures for reliable WT-Logit analysis. In unreported regressions we found some evidence that highly educated entrepreneurs consume less alcohol and use less often sleeping pills than similarly educated employees. However, these results are not robust enough to warrant more emphasis, as the coefficient on the interaction term between ENT and EDUC could not always be estimated or obtained implausible high values, suggesting poor identification.
} 


\section{Robustness analysis}

As a robustness check we estimated fixed effects ordered Logit models for those dependent variables of ours for which the answers to the original survey question were given on an ordered scale. We followed Ferrer-i-Carbonell and Frijters (2004) who suggested that the model can be estimated as a conditional Logit model when the ordered data are collapsed to binary data with unit (in our case twin pair-year) specific thresholds. The recording of observations to "high" and "low" values is based on comparison of individuals to the twin pair's average answers in a given survey wave. The results produced by this alternative method of estimation were similar to those obtained with the WT-Logit results and are not reported. The main difference to the results obtained with WT-Logit was that we found evidence of non-monotonous work for all entrepreneurs irrespective of their level of education.

In sum, our analysis shows that entrepreneurship offers non-monetary returns in the form of less monotonous work, at the expense of longer working hours and greater responsibilities. These findings only seem to hold for entrepreneurs with a low level of education.

\section{$4 \quad$ Conclusions}

Estimating returns to entrepreneurship is challenging. While it is well-known that controlling reliably for unobserved heterogeneity (e.g. ability, preferences, traits, family effects) is very difficult with cross-sectional data, much less attention has been paid to how entry and exit dynamics affect the standard panel data estimates of the returns to entrepreneurship. Both the FD and FE -estimators rely on within individual variation. The former relies on the potentially peculiar years round occupational shifts, the latter assumes (in the form of the strict exogeneity assump- 
tion) that contemporaneous and future shocks to income do not affect occupational decisions.

We suggest an alternative approach by focusing on twin data. Twin differencing, while not trouble-free, avoids the pitfalls buried in conventional estimators used so far. We apply the different estimators to a large panel data on identical Finnish male twins and find that the OLS and FD estimates in particular are biased.

Since our earnings measure is measured annually and since we find that entrepreneurs with low education work longer hours, our results suggest lower hourly earnings for this group of entrepreneurs, confirming partly the findings of Hamilton (2000). Our within twin pair estimations also suggest that besides working longer hours, entrepreneurs with low education appear to have more responsibilities at work. At the same time they have a lower risk of divorce and face less monotonous work tasks. None of these findings extend to entrepreneurs with high education.

Taken together, our results suggest that the returns-to-entrepreneurship puzzle has more dimensions and heterogeneity to it than has previously been thought. 


\section{References}

Andersson, Pernilla (2008). Happiness and health: Well-being among the self-employed, Journal of Socio-Economics 37(1), pp. 213-236.

Ashenfelter, O. (1978). Estimating the Effect of Training Programs on Earnings, Review of Economics and Statistics 6(1), pp. 47-57.

Ashenfelter, Orley and Krueger, Alan (1994). Estimates of the economic return to schooling from a new sample of twins, American Economic Review 84(5), pp. 1157-1173.

Ashenfelter, Orley and Rouse, Cecilia (1998). Income, schooling and ability: Evidence from a new sample of identical twins, Quarterly Journal of Economics 113(1), pp. 253-284.

Åsterbo, Thomas (2011). The returns to entrepreneurship. In: Cummings, Douglas (ed.): Oxford Handbook of Entrepreneurial Finance, Oxford University Press.

Benz, Matthias and Frey, Bruno S. (2004). Being independent raises happiness at work, Swedish Economic Policy Review 11(2), pp. 95-134.

Berglann, Helge, Moen, Espen R., Røed, Knut, and Skogstrøm, Jens Henrik (2011). Entrepreneurship: Origins and returns, Labour Economics 18, pp. 180-193.

Blanchflower, David (2000). Self-employment in OECD countries, Labour Economics 7(5), pp. 471-505.

Blanchflower, David and Oswald, Andrew (1998). What makes and entrepreneur?, Journal of Labor Economics 16(1), pp. 26-60.

Bruce, Donald and Schuetze, Herbert (2004). The labour market consequences of experience in self-employment, $L a$ bour Economics 11(5), pp. 575-598.

Bonjour, Dorthe, Cherkas, Lynn, Haskel, Jonathan, Hawkes, Denise, and Spector, Tim (2003). Returns to education: Evidence from U.K. twins, American Economic Review 93(5), pp. 1799-1812.

Bound, John and Solon, Gary (1999). Double trouble: on the value of twins-based estimation of the return to schooling. Economics of Education Review 18(2), pp. 169-182.

Carlin, John, Gurrin, Lyle, Sterne, Jonathan, Morley, Ruth and Dwyer, Terry (2005). Regression models for twin studies: A critical review, International Journal of Epidemiology 34(5), pp. 1089-1099.

Carrington, William J., McCue, Kristin, and Pierce, Brooks (1996). The role of employer/employee interactions in labour market cycles: Evidence from the self-employed, Journal of Labour Economics 14(4), pp. 571-602.

Chamberlain, Gary (1980). Analysis of covariance with qualitative data, Review of Economic Studies 47(1), pp. 225238.

Dunn, Thomas and Holtz-Eakin, Douglas (2000). Financial capital, human capital and the transition to selfemployment: Evidence from intergenerational links, Journal of Labor Economics 18(2), pp. 282-305.

Evans, David and Leighton, Linda (1989). Some empirical aspects of entrepreneurship, American Economic Review 79(3), pp. 519-535.

Fairlie, Robert W. (1995). Self-employment, entrepreneurship, and the NLSY79, Monthly Labor Review, February, 4047.

Ferrer-i-Carbonell A, Frijters P (2004). How important is methodology for the estimates of the determinants of happiness?, Economic Journal 114(July), pp. 641-659.

Griliches, Zvi (1979). Siblings models and data in economics: beginnings of a survey, Journal of Political Economy 87(5), pp. S37-S64.

Gurrin Lyle, Carlin, John, Sterne, Jonathan, Dite, Gillian and Hopper, John (2006). Using bivariate models to understand between- and within-cluster regression coefficients, with application to twin data, Biometrics, 62(3), pp. 745-51. 
Hamilton, Barton (2000). Does entrepreneurship pay? An empirical analysis of the returns to self-employment, Journal of Political Economy 108(3), pp. 604-631.

Hundley, Greg (2001). Why and when are the self-employed more satisfied with their work?, Industrial Relations 40(2), pp. 293-316.

Hyytinen, Ari and Rouvinen, Petri (2008). The labour market consequences of self-employment spells: European evidence, Labour Economics 15(2), pp. 246-271.

Isacsson, Gunnar (2007). Twin data vs. longitudinal data to control for unobserved variables in earnings functions Which are the differences?, Oxford Bulletin of Economics and Statistics, 69(3), pp. 339-362

Kaprio, Jaakko, and Koskenvuo, Markku (2002). Genetic and environmental factors in complex diseases: The older Finnish twin cohort, Twin Research, 2002, 5(5), pp. 358-365.

Kaprio, Jaakko, Koskenvuo, Markku, Artimo, Markus, Sarna Seppo, and Rantasalo, Ilari (1979): The Finnish Twin Registry: Baseline Characteristics. Section I. Materials methods, representativeness and results for variables special to twin studies. Kansanterveystieteen julkaisuja M 47.

Kawaguchi, Daiji (2008). Self-employment rents: Evidence from job satisfaction scores, Hitotsubashi Journal of Economics, 49(1), pp. 35-45, 2008.

Neumark, David (1999). Biases in twin estimates of the return to schooling. Economics of Education Review 18(2), pp. 143-148.

Nicolaou, Nicos, Shane, Scott, Cherkas, Lynn, Hunkin, Janice, and Spector, Tim D. (2008). Is the tendency to engage in self-employment genetic?, Management Science 54(1), pp. 167-179.

Nicolaou, Nicos, Shane, Scott, Cherkas, Lynn, and Spector, Tim D. (2008). The influence of sensation seeking in the heritability of entrepreneurship, Strategic Entrepreneurship Journal 2(1), pp 7-21.

Nicolaou, Nicos and Shane, Scott (2009). Can genetic factors influence the likelihood of engaging in entrepreneurial activity?, Journal of Business Venturing 24(1), pp. 1-22.

Shane, Shane, Nicolaou, Nicos, Cherkas, Lynn, Spector, Tim, (2010). Genetics, the big five, and the tendency to be self-employed, Journal of Applied Psychology 95(6), 1154-1162.

Shea, John, (1997). Instrument relevance in multivariate linear models: A simple measure, Review of Economics and Statistics 79, pp. 348-352.

Parker, Simon C. (2009). The Economics of Entrepreneurship, Cambridge: Cambridge University Press.

Rosenzweig, Mark R. and Wolpin, Kenneth I. (2000). "Natural natural experiments“ in Economics, Journal of Economic Literature 38(4), pp. 827-874.

Taylor, Mark (1996). Earnings, independence or unemployment: Why become self-Employed, Oxford Bulletin of Economics and Statistics 58(2), pp. 253-266.

Taylor, Mark (1999). Survival of the fittest? An analysis of self-employment duration in Britain, Economic Journal 109(March), pp. C140-C155.

Taylor, Mark (2004). Self-employment in Britain: When, who and why?, Swedish Economic Policy Review 11(2), pp. 139-173.

Wooldridge, Jeffrey, M. (2002). Econometric Analysis of Cross Section and Panel Data, The MIT Press: Cambridge, Massachusetts. 
Table 1: Comparison of wages during different occupational periods.

\begin{tabular}{|c|c|c|c|c|c|c|}
\hline & & & $\begin{array}{l}\text { Last year } \\
\text { before entr. }\end{array}$ & $\begin{array}{c}\text { First year } \\
\text { as entr. }\end{array}$ & $\begin{array}{l}\text { Last year } \\
\text { as entr. }\end{array}$ & $\begin{array}{l}\text { First year } \\
\text { after entr. }\end{array}$ \\
\hline & & 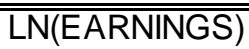 & 10.08 & 10.27 & 10.03 & 9.89 \\
\hline & LN(EARNINGS) & Obs. & 23 & 29 & 34 & 37 \\
\hline Before entr. & 10.21 & 109 & -0.12 & 0.05 & -0.18 & $-0.32^{\star \star}$ \\
\hline During entr. & 10.02 & 206 & 0.06 & 0.24 & 0.01 & -0.13 \\
\hline After entr. & 10.32 & 241 & -0.23 & -0.05 & $-0.28 * \star$ & $-0.42^{\star \star \star}$ \\
\hline
\end{tabular}

Notes: The reported numbers are i) the natural logarithm of earnings (LN(EARNINGS)), ii) the number of observations (Obs.) and iii) in the area bordered from above and left by the dashed lines, the difference between the column variable and the row variable. "Before entr." refers to the average In(earnings) of all observations prior to an entrepreneurial spell, bar the last period before the spell; "During entr." refers to the average of In(earnings) of all entrepreneurship observations, bar the first and last periods before and after an entrepreneurial spell; "After entr." refers to the average of In(earnings) of all observations after an entrepreneurial spell, bar the first period aftert the spell. Significance level: ${ }^{\star \star *} 1 \%,{ }^{* \star} 5 \%,{ }^{\star} 10 \%$.

Table 2: Estimation of monetary returns to entrepreneurship.

\begin{tabular}{|c|c|c|c|c|}
\hline & $\begin{array}{l}\text { Column } 1 \\
\text { OLS }\end{array}$ & $\begin{array}{c}\text { Column } 2 \\
F D\end{array}$ & $\begin{array}{c}\text { Column } 3 \\
\text { FE }\end{array}$ & $\begin{array}{c}\text { Column } 4 \\
\text { WT }\end{array}$ \\
\hline \multirow[t]{2}{*}{ ENT } & $-0.421^{\star \star \star}$ & 0.211 & -0.064 & -0.041 \\
\hline & $(0.139)$ & $(0.271)$ & $(0.197)$ & $(0.175)$ \\
\hline \multirow[t]{2}{*}{ EDUC } & $0.392^{\star \star \star}$ & $0.380^{*}$ & 0.567 & 0.118 \\
\hline & $(0.039)$ & $(0.182)$ & $(0.379)$ & (0.124) \\
\hline \multirow[t]{2}{*}{ ENT*EDUC } & -0.168 & 0.058 & 0.087 & -0.217 \\
\hline & (0.198) & $(0.328)$ & $(0.281)$ & $(0.286)$ \\
\hline Control vector \#1 & Yes & Yes & Yes & Yes \\
\hline Control vector \#2 & Yes & Yes & Yes & Yes \\
\hline Year dummies & Yes & Yes & Yes & Yes \\
\hline Obs. & 7187 & 6324 & 7187 & 3585 \\
\hline R-squared & 0.17 & 0.01 & 0.04 & 0.02 \\
\hline \multirow{2}{*}{$\begin{array}{l}\text { Returns to low educ. } \\
\text { p-value }\end{array}$} & -0.42 & 0.21 & -0.06 & -0.04 \\
\hline & 0.00 & 0.44 & 0.75 & 0.82 \\
\hline \multirow{3}{*}{$\begin{array}{l}\text { Returns to high educ. } \\
\text { p-value } \\
\text { Controls, p-value }\end{array}$} & -0.59 & 0.27 & 0.02 & -0.26 \\
\hline & 0.00 & 0.17 & 0.91 & 0.27 \\
\hline & 0.00 & 0.00 & 0.00 & 0.00 \\
\hline
\end{tabular}

Notes: The dependent variable is LN(EARNINGS). Standard errors are clustered by twin-pairs. Significance level: $\star \star \star ~ 1 \%, * \star 5 \%, * 10 \%$. "Control vector $\# 1 "$ consist of AAGE, AGE2, AGE3, AGE4, HEIGHT90, WEIGHT90, BMI90, UNEMPSHOCK_NEW90, UNEMPSHOCK_OLD90, MARITAL_STATUS90, LIGHTER90, SMOKER90\} except in the last column, where age-variables are not included. "Control vector \#2" consists of \{SCHOOLING, SCHOOLING2, MARITAL_STATUS, HOUSE_OWNER, CHILD_7, CHILD_7_18, DUM_WEALTH, LN(WEALTH)\}. "Returns to low educ." ("Returns to high educ.") refers to the coefficient and p-value of the Wald-test that contrasts the monetary returns of the entrepreneurs with low (high) education to those of the employees with similar education. 
Table 3: IV estimates of monetary returns to entrepreneurship

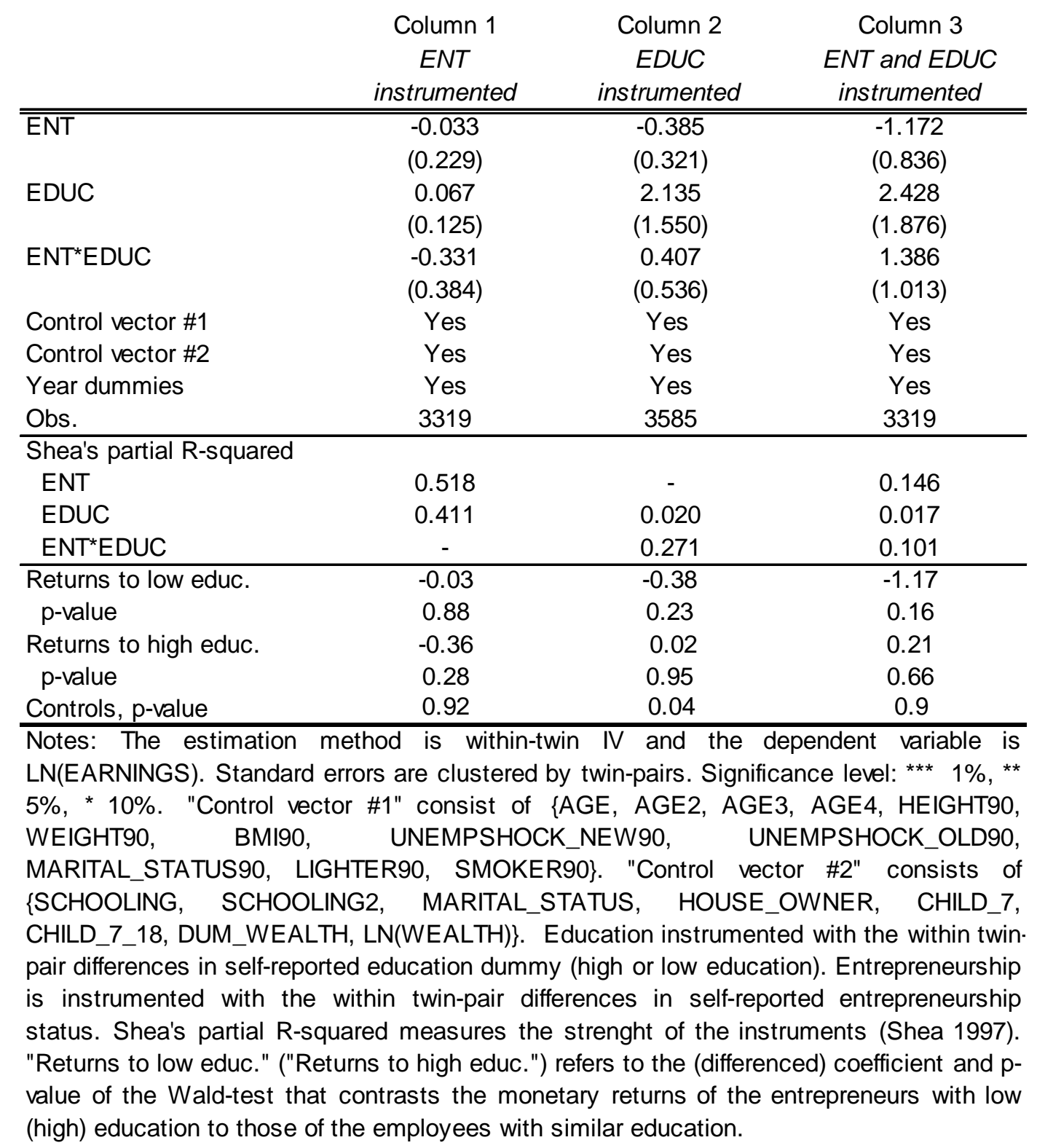


Table 4. Estimation of non-monetary returns to entrepreneurship

\begin{tabular}{|c|c|c|c|c|c|}
\hline \multirow{2}{*}{ Panel A } & Column A1 & Column A2 & Column A3 & Column A4 & Column A5 \\
\hline & $\begin{array}{l}\text { Non- } \\
\text { monotonous } \\
\text { work }\end{array}$ & No overtime & $\begin{array}{c}\text { Working time } \\
\text { at most } 40 \\
\text { hrs. }\end{array}$ & $\begin{array}{l}\text { Influence on } \\
\text { pace of work }\end{array}$ & $\begin{array}{l}\text { Influence on } \\
\text { working } \\
\text { methods }\end{array}$ \\
\hline$\overline{\mathrm{ENNT}}$ & $\begin{array}{c}1.028^{*} \\
(0.547)\end{array}$ & $\begin{array}{c}-1.380^{\star \star \star} \\
(0.475)\end{array}$ & $\begin{array}{c}-1.131^{\star \star} \\
(0.556)\end{array}$ & $\begin{array}{c}0.357 \\
(0.343)\end{array}$ & $\begin{array}{c}0.755 \\
(0.605)\end{array}$ \\
\hline EDUC & $\begin{array}{l}1.255^{*} \\
(0.681)\end{array}$ & $\begin{array}{c}0.266 \\
(0.437)\end{array}$ & $\begin{array}{c}0.686 \\
(0.650)\end{array}$ & $\begin{array}{l}-0.290 \\
(0.569)\end{array}$ & $\begin{array}{c}0.674 \\
(0.808)\end{array}$ \\
\hline ENTEDUC & $\begin{array}{c}-0.430 \\
(1.225)\end{array}$ & $\begin{array}{c}0.860 \\
(1.011)\end{array}$ & $\begin{array}{c}-0.881 \\
(1.542)\end{array}$ & $\begin{array}{c}1.325 \\
(1.148)\end{array}$ & $\begin{array}{c}0.481 \\
(1.277)\end{array}$ \\
\hline Controls & Yes & Yes & Yes & Yes & Yes \\
\hline Year dummies & Yes & Yes & Yes & Yes & Yes \\
\hline Obs. & 866 & 582 & 310 & 672 & 304 \\
\hline Returns to low educ., p-value & 0.06 & 0.00 & 0.04 & 0.30 & 0.21 \\
\hline Returns to high educ., p-value & 0.59 & 0.56 & 0.16 & 0.12 & 0.27 \\
\hline Controls, p-value & 0.18 & 0.02 & 0.08 & 0.82 & 0.05 \\
\hline
\end{tabular}

Notes: The dependent variables are based on survey questions that describe aspects of life which entrepreneurship could influence. They are binary variables, coded so that one always indicates a positive outcome or aspect. Standard errors are clustered by twin-pairs. Significance level: ${ }^{\star \star \star} 1 \%,{ }^{\star \star} \star 5 \%,{ }^{\star} 10 \%$. "Control vector" consists of \{HEIGHT, WEIGHT, BMI, MARITAL_STATUS\}. "Returns to low educ., p-value" ("Returns to high educ., p-value") refers to the p-value of the Wald-test that contrasts the non-monetary returns of the entrepreneurs with low (high) education to those of the employees with similar education. 


\begin{tabular}{|c|c|c|c|c|c|c|c|}
\hline \multirow{2}{*}{ Panel B } & Column B1 & Column B2 & Column B3 & Column B4 & Column B5 & Column B6 & Column B7 \\
\hline & $\begin{array}{c}\text { No divorce or } \\
\text { separation }\end{array}$ & $\begin{array}{l}\text { No increase in } \\
\text { conflicts with } \\
\text { spouse }\end{array}$ & $\begin{array}{l}\text { No significant } \\
\text { increase in } \\
\text { respon- } \\
\text { sibilities at } \\
\text { work }\end{array}$ & $\begin{array}{c}\text { No significant } \\
\text { increase in } \\
\text { work load }\end{array}$ & $\begin{array}{c}\text { Significant } \\
\text { positive } \\
\text { change in life }\end{array}$ & $\begin{array}{c}\text { Significant } \\
\text { positive } \\
\text { change in } \\
\text { working life }\end{array}$ & $\begin{array}{c}\text { Significant } \\
\text { pos. change in } \\
\text { general living } \\
\text { conditions }\end{array}$ \\
\hline \multirow[t]{2}{*}{$\overline{\text { ENT }}$} & $1.446^{\star \star}$ & 0.025 & $-1.079^{\star \star}$ & -0.443 & 0.098 & 0.446 & -0.625 \\
\hline & $(0.639)$ & $(0.339)$ & $(0.480)$ & $(0.349)$ & $(0.389)$ & (0.518) & $(0.537)$ \\
\hline \multirow[t]{2}{*}{ EDUC } & 1.232 & -0.707 & 0.190 & 0.083 & $0.927^{\star}$ & 1.521 & 0.329 \\
\hline & $(0.890)$ & $(0.578)$ & $(0.491)$ & $(0.497)$ & $(0.495)$ & $(1.101)$ & $(0.818)$ \\
\hline \multirow[t]{2}{*}{ ENT*EDUC } & -1.442 & -0.217 & 1.045 & 0.731 & 0.118 & -1.173 & -1.033 \\
\hline & $(1.643)$ & $(0.828)$ & (1.128) & $(0.973)$ & (0.919) & $(1.015)$ & $(1.281)$ \\
\hline Controls & Yes & Yes & Yes & Yes & Yes & Yes & Yes \\
\hline Year dummies & Yes & Yes & Yes & Yes & Yes & Yes & Yes \\
\hline Obs. & 210 & 446 & 536 & 548 & 548 & 228 & 212 \\
\hline Returns to low educ., p-value & 0.02 & 0.94 & 0.02 & 0.20 & 0.80 & 0.39 & 0.24 \\
\hline Returns to high educ., p-value & 1.00 & 0.80 & 0.97 & 0.75 & 0.79 & 0.39 & 0.15 \\
\hline Controls, p-value & 0.00 & 0.34 & 0.25 & 0.51 & 0.04 & 0.63 & 0.60 \\
\hline
\end{tabular}

Notes: See Panel A. 


\begin{tabular}{|c|c|c|c|c|c|c|}
\hline \multirow[b]{2}{*}{ Panel C } & Column C1 & Column C2 & Column C3 & Column C4 & Column C5 & Column C6 \\
\hline & $\begin{array}{c}\text { Moderate } \\
\text { drinking } \\
\text { pattern }\end{array}$ & $\begin{array}{l}\text { Moderate } \\
\text { smoking }\end{array}$ & $\begin{array}{c}\text { No diagnosed } \\
\text { diseases }\end{array}$ & No pain killers & $\begin{array}{c}\text { No } \\
\text { tranquilizers }\end{array}$ & No antacids \\
\hline$\overline{\text { ENT }}$ & $\begin{array}{c}-0.167 \\
(0.290)\end{array}$ & $\begin{array}{c}0.066 \\
(0.294)\end{array}$ & $\begin{array}{c}0.370 \\
(0.251)\end{array}$ & $\begin{array}{l}-0.045 \\
(0.230)\end{array}$ & $\begin{array}{c}0.654 \\
(0.464)\end{array}$ & $\begin{array}{c}-0.295 \\
(0.383)\end{array}$ \\
\hline EDUC & $\begin{array}{c}0.604 \\
(0.485)\end{array}$ & $\begin{array}{l}1.304^{\star \star} \\
(0.528)\end{array}$ & $\begin{array}{l}0.716^{\star} \\
(0.406)\end{array}$ & $\begin{array}{c}0.227 \\
(0.350)\end{array}$ & $\begin{array}{l}-0.967 \\
(0.812)\end{array}$ & $\begin{array}{c}0.593 \\
(0.496)\end{array}$ \\
\hline ENT*EDUC & $\begin{array}{c}0.075 \\
(0.964)\end{array}$ & $\begin{array}{l}-1.693 \\
(1.181)\end{array}$ & $\begin{array}{l}-0.303 \\
(0.661)\end{array}$ & $\begin{array}{l}-1.114 \\
(0.855)\end{array}$ & $\begin{array}{l}-0.349 \\
(1.042)\end{array}$ & $\begin{array}{c}0.252 \\
(0.699)\end{array}$ \\
\hline Controls & Yes & Yes & Yes & Yes & Yes & Yes \\
\hline Year dummies & Yes & Yes & Yes & Yes & Yes & Yes \\
\hline Obs. & 1270 & 1080 & 1618 & 1492 & 394 & 738 \\
\hline Returns to low educ., $p$-value & 0.56 & 0.82 & 0.14 & 0.85 & 0.16 & 0.44 \\
\hline Returns to high educ., $\mathrm{p}$-value & 0.92 & 0.15 & 0.91 & 0.17 & 0.75 & 0.94 \\
\hline Controls, p-value & 0.00 & 0.00 & 0.08 & 0.70 & 0.01 & 0.03 \\
\hline
\end{tabular}




\section{Appendix 1. Descriptive statistics}

Table A1: Descriptive statistics: Data for the analysis of monetary returns

\begin{tabular}{|c|c|c|c|c|c|}
\hline Variable & Obs. & Mean & Std. Dev. & Min & $\operatorname{Max}$ \\
\hline LN(EARNINGS) & 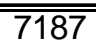 & 10.200 & 0.757 & 1.339 & 13.976 \\
\hline ENT & 7187 & 0.126 & 0.332 & 0 & 1 \\
\hline EDUC & 7187 & 0.370 & 0.483 & 0 & 1 \\
\hline ENT*EDUC & 7187 & 0.043 & 0.203 & 0 & 1 \\
\hline AGE & 7187 & 49.130 & 6.009 & 36 & 68 \\
\hline HEIGHT90 & 7187 & 176.391 & 6.199 & 157 & 196 \\
\hline WEIGHT90 & 7187 & 77.002 & 11.002 & 50 & 120 \\
\hline BMI90 & 7187 & 24.718 & 3.058 & 16.541 & 37.551 \\
\hline UNEMP_SHOCK_NEW90 & 7187 & 0.049 & 0.216 & 0 & 1 \\
\hline UNEMP_SHOCK_OLD90 & 7187 & 0.036 & 0.185 & 0 & 1 \\
\hline MARITAL_STATUS90 & 7187 & 0.825 & 0.380 & 0 & 1 \\
\hline LIGHTER90 & 7187 & 0.135 & 0.341 & 0 & 1 \\
\hline SMOKER90 & 7187 & 0.612 & 0.487 & 0 & 1 \\
\hline MARITAL_STATUS & 7187 & 0.430 & 0.495 & 0 & 1 \\
\hline HOUSE_OWNER & 7187 & 0.861 & 0.346 & 0 & 1 \\
\hline CHILD_7 & 7187 & 0.130 & 0.438 & 0 & 4 \\
\hline CHILD_7_18 & 7187 & 0.599 & 0.922 & 0 & 7 \\
\hline DUM_WEALTH & 7187 & 0.677 & 0.468 & 0 & 1 \\
\hline LN(WEALTH) & 7187 & 6.704 & 4.737 & 0 & 14.900 \\
\hline
\end{tabular}

Notes: This table displays the descriptive statistics for the data used to estimate monetary returns to entrepreneurship. The sources of the data are the 1990 wave of the Finnish twin survey and the Finnish Longitudinal Employer-Employee Data of Statistics Finland. 
Table A2: Descriptive statistics: Data for the analysis of non-monetary returns

\begin{tabular}{|c|c|c|c|c|c|}
\hline Variable & Obs & Mean & Std.Dev. & Min & $\operatorname{Max}$ \\
\hline $\bar{E}$ ENT & $4 \quad 4686$ & 0.102 & 0.302 & 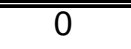 & 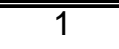 \\
\hline EDUC & 4526 & 0.128 & 0.334 & 0 & 1 \\
\hline ENT*EDUC & 4526 & 0.009 & 0.092 & 0 & 1 \\
\hline HEIGHT & 4673 & 175.43 & 6.210 & 152 & 196 \\
\hline WEIGHT & 4666 & 74.551 & 10.190 & 46 & 130 \\
\hline $\mathrm{BMI}$ & 4658 & 24.203 & 2.896 & 16.412 & 38.398 \\
\hline MARRIED & 4681 & 0.737 & 0.441 & 0 & 1 \\
\hline Non-monotonous work & 4592 & 0.852 & 0.355 & 0 & 1 \\
\hline No overtime & 1818 & 0.495 & 0.500 & 0 & 1 \\
\hline Working at most 40 hours & 925 & 0.344 & 0.475 & 0 & 1 \\
\hline Influence on pace of work & 1831 & 0.554 & 0.497 & 0 & 1 \\
\hline Influence on working methods & 926 & 0.612 & 0.487 & 0 & 1 \\
\hline No divorce or separation & 2661 & 0.953 & 0.212 & 0 & 1 \\
\hline No increase in conflicts with spouse & 2645 & 0.875 & 0.331 & 0 & 1 \\
\hline No significant increase in responsibilities at work & 1760 & 0.622 & 0.485 & 0 & 1 \\
\hline No significant increase in work load & 1742 & 0.587 & 0.492 & 0 & 1 \\
\hline Significant positive change in life & 1768 & 0.343 & 0.475 & 0 & 1 \\
\hline Significant positive change in work life & 903 & 0.288 & 0.453 & 0 & 1 \\
\hline Significant pos. change in general living conditions & 905 & 0.251 & 0.434 & 0 & 1 \\
\hline Moderate drinking pattern & 4656 & 0.574 & 0.495 & 0 & 1 \\
\hline Moderate smoking & 4639 & 0.618 & 0.486 & 0 & 1 \\
\hline No diagnosed diseases & 4686 & 0.546 & 0.498 & 0 & 1 \\
\hline No pain killers & 4575 & 0.441 & 0.497 & 0 & 1 \\
\hline No tranquillizers & 4518 & 0.940 & 0.237 & 0 & 1 \\
\hline No antacids & 4520 & 0.857 & 0.350 & 0 & 1 \\
\hline
\end{tabular}

Notes: This table displays the descriptive statistics for the twin survey data used to estimate non-monetary returns to entrepreneurship. The sources of the data are the three waves (1975, $1981,1990)$ of the Finnish twin survey. Due to non-response and changes in the survey questions over the survey waves, the number of observations vary from question to question. 